\title{
The Influence of Socio-Economic Status on the Prevalence of School-Age Childhood Behavioral Disorders in a Local District Clinic of North West England
}

\author{
Michael O. Ogundele \\ Bridgewater Community Healthcare NHS Foundation Trust, Halton and St Helens Community Pediatrics Dept, Runcorn, UK
}

\author{
Email address: \\ m.ogundele@nhs.net
}

To cite this article:

Michael O. Ogundele. The Influence of Socio-Economic Status on the Prevalence of School-Age Childhood Behavioral Disorders in a Local District Clinic of North West England. Journal of Family Medicine and Health Care. Vol. 2, No. 4, 2016, pp. 98-107.

doi: $10.11648 /$ j.jfmhc.20160204.22

Received: September 18, 2016; Accepted: November 4, 2016; Published: December 9, 2016

\begin{abstract}
There are several types of childhood behavioral disorders. The most common disruptive behavior disorders include ODD, CD and ADHD. Socio-economic factors are known to influence the prevalence of chronic childhood disabling conditions including emotional and behavioral disorders. Assessment of school-age children for difficult or challenging behavior constitutes a major case load of neurodevelopmental pediatricians (mainly designated as community pediatricians) and child/adolescent psychiatrists in the UK. We aimed to evaluate the influence of the socio-economic status among schoolage children on the distribution and types of behavioral disorders, including ADHD, in a local district Community Pediatric unit of a large healthcare NHS Foundation Trust in the North West of England. The record of all the patients who were seen in any outpatient clinic over a 22-month period between Jan 2014 and Oct 2015 were retrospectively analyzed. Information was collected on the range of clinical presentation and socioeconomic characteristics. The socio-economic status of each child was determined using the latest published Index of Multiple Deprivation (IMD) 2015. A total of 201 school-age children were referred ( 9 monthly), corresponding to an average of $31 \%$ of total monthly caseload. The proportion of patients living in the most deprived deciles and quintiles was 39\% and 70\% respectively. The prevalence in the most deprived decile (11.6/1000) was 193 times that of the most affluent area. History of family and social adversities was common among the patients including separated parents (24\%), fostered / adopted (11\%) and previous exposure to abuse, domestic violence or neglect $(9 \%)$. Socioeconomic deprivation is significantly associated with the prevalence of behavior problems in children living in the North-West of England. Poverty-related chronic stressors are hypothesized to cumulatively compromise parental psychology and ultimately childhood behavioral and mental health outcomes. Tackling the problem requires integrated multidisciplinary and multi-agency approach.
\end{abstract}

Keywords: Child, Behavior, Attention Deficit and Disruptive Behavior Disorders, Epidemiology, Conduct Disorder

\section{Introduction}

There are several types of childhood behavioral disorders including disruptive, emotional, anxiety and pervasive developmental disorders (PDD). The most common disruptive behavior disorders include oppositional defiant disorder (ODD), conduct disorder (CD) and attention deficit hyperactivity disorder (ADHD). Conduct disorder (CD) is described in DSM-V and is one of the most difficult and intractable problems in children and adolescents. It involves "a repetitive and persistent pattern" of various antisocial behavior consisting of aggressive and delinquent acts which result in physical or psychological harm to others or their property (e.g., 'stealing', 'lying', and 'getting into fights'), with such behaviors violating the rights of others and, in some cases, violate legal codes, associated with heavy costs to society [1].

Childhood behavioral disorders often precede, or co-occur with emotional symptoms, especially childhood depression, associated with violent behavior and criminality through 
adulthood [2, 3]. Childhood behavioral disorders are also associated with increased future risks of adult partnership difficulties, inter-partner conflict/violence, lower levels of relationship satisfaction and parenting difficulties, including over-reactivity, lax and inconsistent discipline, child physical punishment and lower levels of parental warmth and sensitivity [4].

Accumulating evidence suggests that perinatal risk factors (maternal gestational smoking and drug use, early labor, low birth weight, and infant breathing problems at birth) are important precursors of childhood Disruptive behavior disorders (DBDs), including attention-deficit/hyperactivity disorder (ADHD), oppositional defiant disorder (ODD) and conduct disorder (CD) [5, 6]. However, no consistent evidence has been found for any detrimental effect of intrauterine exposure to caffeine on offspring's early childhood problem behavior or emotional problems [7]. Maternal smoking of 10 cigarettes or more per day during pregnancy is associated with early onset of behavior disorders among the offspring [8]. Growing body of research evidence also link postnatal secondhand smoke exposure with conduct and various emotional disorders in children [9]. Prematurity and low birthweight are also reported to significantly increase the risk for behavioral and mental health problems among children [10]. Parental mental health problems are also independently associated with childhood behavior disorders and co-morbid anxiety disorder and depression [11]. Other parental heritable factors may also predispose to childhood behavioral disorders. The availability of the Dopamine transporter (DAT) in the basal ganglia, caudate nucleus, and putamen has been reported to be significantly lower in parents with ADHD offspring [12].

Several other adverse social and environmental factors have been shown to predispose to childhood behavioral disorders including exposure to socioeconomic adversity; parental maladaptive behavior; childhood exposure to abuse and inter-parental violence; low cognitive ability, and affiliation with deviant peers in early adolescence [13].

Chronic stressors associated with poverty are widely believed to be at least part of the explanation of the link between socioeconomic status (SES) and behavioral disorders [1]. Chronis stress resulting from adverse environmental factors including exposure to high levels of crime, discord and other threatening and uncontrollable events can lead to a pattern of behavior known as 'reactive responding' characterized by chronic vigilance, emotional reacting and sense of powerlessness [14]. Ability to parent effectively is also significantly impaired among families living within low-SES contexts, leading to overuse of negative control strategies, failure to adequately monitor children and exhibiting low warmth and responsiveness [15].

Several detailed studies of functional scans in children with behavioral disorders suggest there are underlying subtle neurobiological changes in different parts of the brain including the hypothalamus, inferior and superior parietal lobes, right amygdala and anterior insula [16, 17]. There is also evidence to suggest a moderate risk of genetic inheritability in children with conduct disorders from their parents [18].

Assessment of school-age children for difficult or challenging behavior constitutes a major case load of neurodevelopmental pediatricians (mainly designated as community pediatricians) and child/adolescent psychiatrists in the UK. There is no single diagnostic tool available for the confirmation of childhood behavioral disorders. Diagnosis is usually based on various combinations of subjective reports of parental, teachers, professional or other observer feedback on a variety of psychometric questionnaires or screening tools. There is often a marked discrepancy between various respondents. The published literature suggests that parents often report more symptoms and diagnoses of ODD and CD than teachers, and mother-teacher agreement is often low except when the behavior report feedback is obtained within the same context [19].

Management of childhood behavioral disorders can be quite challenging for the individual families and the community. Parent-based and child-based approaches have been reported with variable degrees of success. A recent Cochrane review of 13 studies confirmed that behavioral and cognitive-behavioral group-based parenting interventions are effective and cost-effective for improving child conduct problems, parental mental health and parenting skills in the short term [20]. A school-based Child-focused cognitive behavioral therapy (CBT) program in disadvantaged settings with or without active teacher support (ATS) has been shown to effectively improve childhood disruptive behaviors [21].

There are some practical and simple preventive measures to reduce the prevalence of behavior disorders that have been reported including breastfeeding and avoidance of secondhand smoke exposure in children and youths who are not themselves cigarette smokers [9, 22]. Another ambitious effective preventive strategy includes reduction of worldwide socio-economic inequalities that are responsible for a high rate of mortality and social and emotional well being disparities. This is one of the most challenging World Health Organization (WHO) targeted ambitions [23, 24].

\section{Methods}

We aimed to evaluate the characteristics of school-age children who were on the clinical caseload of a local district community pediatric unit at a large healthcare NHS Foundation Trust in the North West of England. These children were referred for concerns about their behavior. The record of all the patients who were seen in any outpatient clinic over a 22-month period between Jan 2014 and Oct 2015 were retrospectively analyzed. Information was collected on the range of clinical presentation, socioeconomic characteristics, assessment duration and schedule of followup. The audit was completed as part of the Clinical Governance strategies of the Bridgewater Community Healthcare Foundation Trust. No identifiable patient record was used and no research ethical approval was required.

The study includes all school-age children referred for 
challenging behavioral problems not explained by any specific genetic or neurodevelopmental disorders. The demographics and clinical characteristics of all children diagnosed with ADHD were compared with those with no specific neurodevelopmental diagnosis.

\subsection{Socioeconomic Determinants}

The socio-economic status of each child was determined using the latest published Index of Multiple Deprivation (IMD) 2015, which measures relative levels of deprivation in 32,844 small areas or neighbourhoods, called Lower-layer Super Output Areas (LSOA), in England. The IMD 2015 is calculated from 7 weighted categories (domains) based on 37 separate indicators. The 7 domains are Income; Employment; Education, Skills and Training; Health Deprivation and Disability; Crime; Barriers to Housing and Services; and Living Environment (Table 1).

Table 1. The seven domains and the relative weighting ${ }^{\ddagger}$ used to calculate the $I M D^{\beta} 2015$.

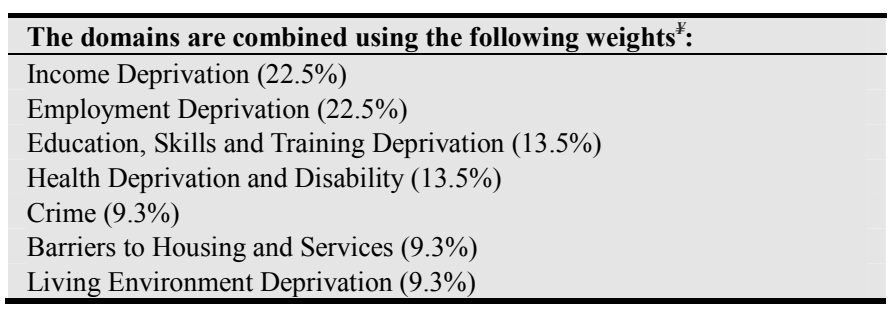

Legend: ${ }^{¥}$ The weights were derived from consideration of the academic literature on poverty and deprivation, as well as consideration of the levels of robustness of the indicators.

${ }^{\beta}$ Index of Multiple Deprivation

We identified the LSOA for each patient using the residential postcodes. The deciles and quintiles are calculated by dividing the 32,844 LSOAs into 10 and 5 equal groups respectively. LSOAs in decile 1 fall within the most deprived $10 \%$ of LSOAs nationally and LSOAs in decile 10 fall within the least deprived $10 \%$ of LSOAs nationally.

\subsection{Statistical Analysis}

Spearman's rank correlation coefficient was used to determine the relationship between the prevalence of ADHD or other behavior problems in different Quintiles and Deciles of the local District authority's LSOAs. Student's T test was used to compare percentages or mean from two independent samples. Chi square (with Yates correction when relevant) was used for comparison of multiple proportions among groups of patients. Statistical significance is accepted at the $p$ value of $<0.05$.

\section{Results}

\subsection{Local Population and Service Description}

Halton is the 19th of the 20 English local authority districts with the highest proportion of their neighbourhoods (21 out of 80 ) in the most deprived 10 per cent of neighbourhoods nationally on the Index of Multiple Deprivation 2015[25].

The estimated school age childhood population of Halton local district is $16432,13 \%$ of total population of 126,400 (Mid 2014 estimate) with a birth rate of 1522 and sex distribution of $49 \%$ male and $51 \%$ female.

The community pediatric unit (CPU) is a secondary care level for childhood developmental and behavior problems and is usually the initial referral point for mild to moderate emotional difficulties in children and adolescents. Referrals are accepted from a wide range of primary healthcare professionals including the GP, children social services, allied healthcare therapists and from the educational sector.

The CPU has a direct link with the two local District General Hospitals (DGH) in Warrington and Whiston for access to laboratory pathology and radiological investigation services and to a tertiary children's hospital in Liverpool for specialist expertise.

\subsection{Examples of Clinical Case Vignettes}

Case 1

$\mathrm{JJ}$ is a 7-year old boy presenting with longstanding parental concerns regarding his uncontrollable anger, poor attention skills, violent behavior and impulsivity. $\mathrm{JJ}$ is hyperactive, loses temper without much trigger, and he is very violent towards his mum. JJ is often physically and verbally very aggressive. He becomes abusive to adults or peers when he does not get his own way. He becomes physically violent, throws and breaks stuff and smashes whatever he can lay his hands on. Mum informed that JJ is defiant, gets into a fight about everything and has constant arguments with parents and teachers.

JJ's parents are divorced and he lives with his mum who is remarried with a new partner. JJ does not get on very well with his mum's new partner and sometimes he says "you are not my dad".

JJ looked well in the clinic. He was well behaved and polite during the consultation. He was co-operative, followed all the instructions with ease. $\mathrm{He}$ was sociable and interactive. He played on his mum's i-phone during most of the appointment. He was occasionally restless and he got up from his chair a few times to explore some toys in the room.

The systemic examination was entirely normal. His height was between $50^{\text {th }}-75^{\text {th }}$ centile, and his weight on the $50^{\text {th }}$ centile. The rest of the systemic examinations were unremarkable.

$\mathrm{JJ}$ was further assessed for ADHD, ODD and CD using the SNAP IV questionnaires to collect information from home and school. The scores suggested high risk for ADHD, ODD but not CD.

Case 2

Jane is an 11-year old school girl who presented with both parents for concerns about her challenging behavior which has escalated since starting high school. Jane swears a lot, often using the ' $\mathrm{f}$ ' words addressed to adults and other peers at school. She kicks, bites, smacks, punches and throws things at her Mum. Her behavior is worse if she is not getting her own way. Mum has tried using various consequences 
including withdrawal of benefits such as grounding in her room, not going out with friends, confiscating her mobile phone etc without any consistent success. Jane's behavior is more manageable when her Dad is around.

Jane was obviously upset and she was not pleased to be in the clinic. She was frequently argumentative with her Mum and often interrupted her explanations.

Jane's general and systemic examination was normal apart from being slightly overweight with Body Mass Index (BMI) on the $98^{\text {th }}$ centile for her age.

Jane's parents and teachers completed the SNAP IV questionnaires to screen for a diagnosis of ADHD, ODD or CD. The combined scores from home and school did not support a diagnosis of ADHD but was strongly supportive of ODD and CD.

\subsection{Demographic Characteristics}

A total of 201 school-age children were referred (average of 9 per month), corresponding to an average of $31 \%$ of total monthly Community Pediatric caseload. This corresponds to a prevalence of $0.7 \%$ annually of the school-age childhood population. A total of 23 referrals were rejected without undertaking any assessment. ADHD assessment with standard questionnaires was undertaken in 99 of the remaining 178 cases seen $(56 \%)$ but the diagnosis was confirmed in only 33 of them ( $67 \%$ negative).

The male-female ratio for all the referrals was 3.2:1 but this was almost double (5.6:1) in the group of ADHD children (Table 2). Mean age at referral was 8 years 6 months, with standard deviation (SD 35 months). Each patient attended on average 2 outpatient clinics with an average follow-up duration of 7 months. There were no significant statistical differences in the demographic and clinical characteristics between the two groups (those diagnosed with ADHD and those with no ADHD diagnosis) apart from the mean number of clinics attended (2.6 vs 1.8) and the duration of the clinical assessment (11.6 vs 6.1 months). The clinical assessment of ADHD was often prolonged by the need to gather additional information and feedback on screening questionnaires from the school and the parents.

Table 2. Comparing clinical and epidemiological characteristics of ADHD and non-ADHD behavior patients.

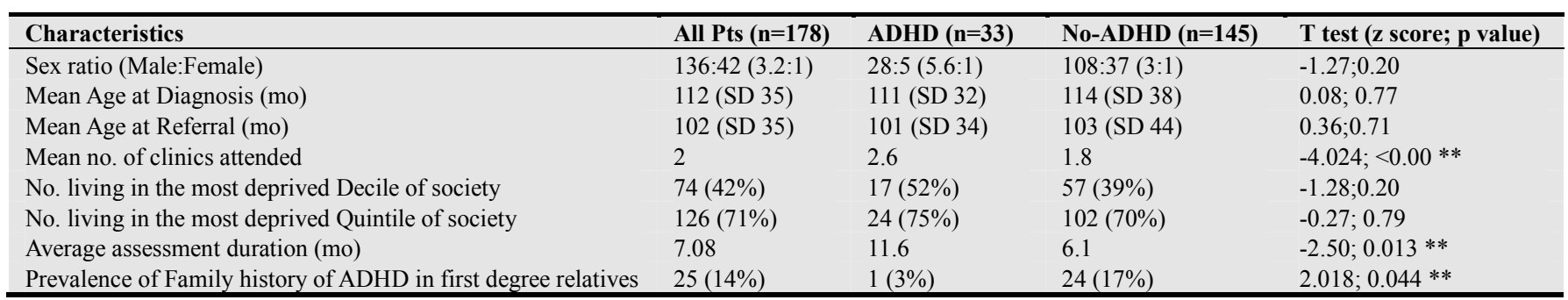

Legend: mo:Months

SD: Standard Deviation (in months)

$* *$ Statistically significant at $\mathrm{p}<0.05$

There was a positive family history of ADHD among first degree relatives in 25 cases $(14 \%)$. The prevalence was higher among children with no diagnosis of ADHD (17\% vs $3 \%$ ).

\subsection{Socioeconomic Characteristics}

There was a strong linear relationship between the socioeconomic deprivation and the prevalence of behavioral disorders in the school-age children (Figure 1). The largest proportion of the patients were living in the most deprived deciles and quintiles of the society $(39 \%$ and $70 \%$ respectively) (Table 3, Figure 1). The prevalence in the most deprived decile $(11.6 / 1000)$ was 193 times the prevalence in the most affluent decile areas $(0.06 / 1000)$, Spearman Rank Correlation -0.83 , and the 2 -sided p-value 0.006 .

Table 3. The distribution of patients with behavior problems according to LSOA Quintiles ${ }^{t}$.

\begin{tabular}{|c|c|c|c|}
\hline Nat Quintile & No_Pts (\% of Total) & Prev $^{\beta}$ & Sch-Age Population \\
\hline Quintile 1 (Most Deprived) & $102(70 \%)$ & 11.86651 & 8511 \\
\hline Quintile 2 & $17(12 \%)$ & 8.13083 & 2091 \\
\hline Quintile 3 & $12(8 \%)$ & 7.154317 & 1677 \\
\hline Quintile 4 & $7(5 \%)$ & 3.054464 & 2292 \\
\hline Quintile 5 & $7(5 \%)$ & 3.707962 & 1888 \\
\hline Total & 145 & 8.8 & 16459 \\
\hline
\end{tabular}

Legend: ${ }^{\beta}$ Prevalence per 1000 childhood population

${ }^{\text {f}}$ Spearman Rank Correlation -0.9 and 2-sided p-value 0.0833 

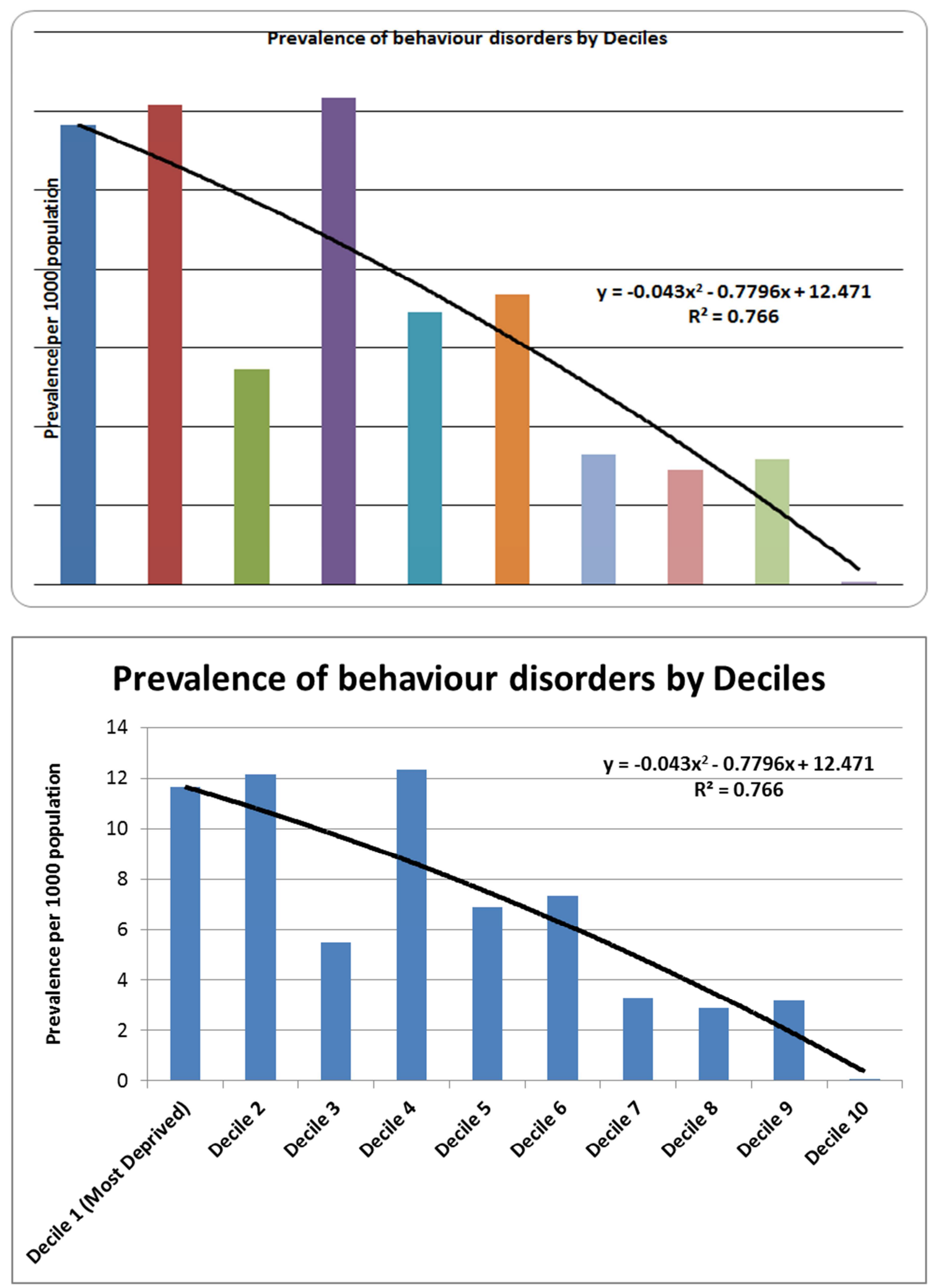

Spearman Rank Correlation -0.83 and 2-sided p-value 0.006

Figure 1. The prevalence of childhood behavior problems by deciles of Halton LSOAs.

There was a high incidence of family adversities and social problems including separated parents (24\%), fostered / adopted $(10 \%)$ and previous exposure to abuse, domestic violence or neglect (8.4\%) (Table 4). 
Table 4. Comparing Neurodevelopmental and psychosocial co-morbidities among ADHD and non-ADHD patients.

\begin{tabular}{|c|c|c|c|c|c|c|c|}
\hline \multirow{2}{*}{ Co-morbidities } & \multicolumn{2}{|c|}{ All Patients $n=178$} & \multicolumn{2}{|c|}{ Non-ADHD n=145 } & \multicolumn{2}{|c|}{ ADHD n=33 } & \multirow{2}{*}{ T test (Z-Score; $p$-value) } \\
\hline & No. Pts & $\%$ & No. Pts & $\%$ & No. Pts & $\%$ & \\
\hline Sleep & 69 & 38.8 & 57 & 39.3 & 12 & 36.4 & $0.3136 ; 0.76$ \\
\hline SC Concerns & 38 & 21.3 & 35 & 24.1 & 3 & 9.1 & $1.9039 ; 0.057$ \\
\hline Family-separated & 42 & 23.6 & 35 & 24.1 & 7 & 21.2 & $0.3573 ; 0.719$ \\
\hline LD & 42 & 23.6 & 34 & 23.4 & 8 & 24.2 & $-0.097 ; 0.92$ \\
\hline DCD & 22 & 12.4 & 20 & 13.8 & 2 & 6.1 & $1.2181 ; 0.222$ \\
\hline LAC / Adopted & 18 & 10.1 & 16 & 11.0 & 2 & 6.1 & $0.8554 ; 0.39$ \\
\hline SAL Delay & 17 & 9.6 & 13 & 9.0 & 4 & 12.1 & $-0.5567 ; 0.58$ \\
\hline Social $^{\beta}$ & 15 & 8.4 & 13 & 9.0 & 2 & 6.1 & $0.5422 ; 0.59$ \\
\hline Dev delay /immaturity & 14 & 7.9 & 14 & 9.7 & 0 & 0 & $1.8596 ; 0.063$ \\
\hline Emotional $^{\$}$ & 14 & 7.9 & 14 & 9.7 & 0 & 0 & $1.8596 ; 0.063$ \\
\hline Sensory & 13 & 7.3 & 11 & 7.6 & 2 & 6.1 & $0.304 ; 0.76$ \\
\hline $\mathrm{CD}, \mathrm{ODD}$ & 8 & 4.5 & 7 & 4.8 & 1 & 3 & $0.4498 ; 0.65$ \\
\hline Enuresis & 7 & 3.9 & 7 & 4.8 & 0 & 0 & $1.2878 ; 0.20$ \\
\hline Tics & 5 & 2.8 & 2 & 1.4 & 3 & 9.1 & $-2.42 ; 0.015^{* *}$ \\
\hline Obesity & 4 & 2.2 & 4 & 2.8 & 0 & 0 & $0.965 ; 0.33$ \\
\hline Smoker/drugs & 4 & 2.2 & 4 & 2.8 & 0 & 0 & $0.965 ; 0.33$ \\
\hline Sch attendance & 3 & 1.7 & 3 & 2.1 & 0 & 0 & $0.8333 ; 0.41$ \\
\hline Epilepsy/NF1 & 3 & 1.7 & 2 & 1.4 & 1 & 3 & $-0.665 ; 0.51$ \\
\hline Deafness & 2 & 1.1 & 2 & 1.4 & 0 & 0 & $0.68 ; 0.50$ \\
\hline Heart disorders & 2 & 1.1 & 0 & 0.0 & 2 & 6.1 & $-2.98 ; 0.003 * *$ \\
\hline
\end{tabular}

Legend:

Diff: Difficulties

Dev: Developmental

LD: Learning Difficulties

DCD: Developmental Coordination Disorder (Dyspraxia)

LAC: Looked After Child (by Local Authority)

SAL: Speech and language

SC: Social Communication

CD/ODD: Conduct Disorder/Oppositional Defiant Disorder

FH: Family History

DV: Domestic violence

ASD: Autistic Spectrum Disorder

CHD: Congenital Heart Diseases

NF: Neurofibromatosis

${ }^{\$}$ Anxiety, low self-esteem, attachment problems

${ }^{\beta}$ Social problems including Domestic Violence, abuse, neglect, Social Service provisions

** Statistically significant

\subsection{Associated Co-morbidities}

Co-morbid neurodevelopmental disorders and psychosocial adversities were common among the patients (Table 4). Only 13 patients had no other co-morbidities while each of the remaining patients had on average 2 . The commonest neurodevelopmental co-morbidities included sleep difficulties (39\%), Social Communication concerns (21\%), learning difficulties (24\%), dyspraxia (12\%), speech delay $(10 \%)$ and other developmental immaturity (8\%). $8 \%$ of the children had emotional problems including attachment difficulties. The number and distribution of co-morbid problems in both groups were similar apart from higher incidence of tics and heart disorders in the group children with ADHD.

The ADHD children also had significantly lower average number of co-morbidities compared with those without ADHD (2.1 vs 1.6) (T-value 2.35 and 2-tailed $p$ value 0.02 ).
However the distribution of the number of co-morbidities per patient was similar between both groups (Yates' Chi sq = $3.76, \mathrm{p}$ value $=0.81)$.

\subsection{Sources of Referral}

At least thirteen different sources of referral were identified (Table 5). The commonest sources of referrals were the General Practitioners (GP) (65\%), Educational staff (Nurses, Managers, Welfare Officers and Psychologists (22\%), Child and Adolescent Mental Health Service (CAMHS) (5\%) and Multidisciplinary teams (4\%).

There were statistical significance differences between the proportion of children referred by CAMHS, Educational psychologist and Autism pathway team among children diagnosed with ADHD and those without ADHD, but the actual numbers of the referred children were similar (Table 5). 
Table 5. Sources of referral.

\begin{tabular}{|c|c|c|c|c|c|c|c|c|}
\hline Source & Referrer & All Patients $\mathrm{N}=178$ & $\%$ & Non-ADHD N=145 & $\%$ & ADHD N=33 & $\%$ & T test (Z-Score; p-value) \\
\hline \multirow[t]{2}{*}{ Pry Care } & GP & 116 & 65.2 & 97 & 66.9 & 19 & 57.6 & $1.014 ; 0.31$ \\
\hline & Sch Nurse & 27 & 15.2 & 23 & 15.9 & 4 & 12.1 & $0.54 ; 0.59$ \\
\hline \multirow{4}{*}{$\begin{array}{l}\text { School/Educational } \\
\text { staff }\end{array}$} & SENCo & 4 & 2.2 & 3 & 2.1 & 1 & 3.0 & $-0.34 ; 0.73$ \\
\hline & Edu WO & 4 & 2.2 & 3 & 2.1 & 1 & 3.0 & $-0.34 ; 0.73$ \\
\hline & SchMgr & 2 & 1.1 & 2 & 1.4 & 0 & 0 & $0.68 ; 0.50$ \\
\hline & EduPsy & 2 & 1.1 & 0 & 0 & 2 & 6.1 & $-2.98 ; 0.002 * *$ \\
\hline Mental Health & CAMHS & 9 & 5.1 & 5 & 3.4 & 4 & 12.1 & $-2.05 ; 0.040 * *$ \\
\hline \multirow{4}{*}{$\begin{array}{l}\text { Multidisciplinary } \\
\text { teams } \\
\text { Secondary care }\end{array}$} & Beh Team & 6 & 3.4 & 6 & 4.1 & 0 & 0 & $1.19 ; 0.23$ \\
\hline & SC Path & 1 & 0.6 & 0 & 0 & 1 & 3.0 & $-2.10 ; 0.036^{* *}$ \\
\hline & Gen Paed & 4 & 2.2 & 4 & 2.8 & 0 & 0 & $0.96 ; 0.33$ \\
\hline & Cont Nurse & 1 & 0.6 & 1 & 0.7 & 0 & 0 & $0.48 ; 0.63$ \\
\hline \multirow[t]{2}{*}{ Allied Healthcare } & Audiology & 1 & 0.6 & 1 & 0.7 & 0 & 0 & $0.48 ; 0.63$ \\
\hline & SALT & 1 & 0.6 & 0 & 0 & 1 & 3.0 & $-2.10 ; 0.036^{* *}$ \\
\hline
\end{tabular}

Legend: GP: General Practitioners

CAMHS: Child and Adolescent Mental Health Service

SENCo: Special Educational Needs Coordinator

Beh Team: Behavioral Multidisciplinary Team

SC Path: Social Communication/Autism Pathway team

Edu WO: Educational Welfare Officer

SchMgr: School Manager

Cont Nurse: Continence Nurse

SALT: Speech/Language Therapist

EduPsy: Educational Psychologist

** Statistically significant

\subsection{Clinical Outcome}

A significantly larger proportion of non-ADHD patients were discharged from the clinics. Three of the ADHD patients (9\%) compared with 55 (38\%) among the nonADHD patients were discharged during the study period (ZScore 3.19, p-value 0.0014). Two of the ADHD patients (6\%) and seven non-ADHD patients $(5 \%)$ failed to attend their clinic (Z-Score -0.29 , p-value 0.77). The patients that were screened for ADHD with the Swanson, Nolan, and Pelham IV Questionnaire (SNAP-IV - 26-item freely available resource online at myadhd.com) were either confirmed with a diagnosis of ADHD, oppositional defiant disorder (ODD) or conduct disorder (CD). None of them had "persistent and significant mental health impairment' threshold for a referral to Child and Adolescent mental health services (CAMHS). All the parents were signposted for self-referral to locally available group parenting programs.

\section{Discussion}

Large epidemiology studies in other affluent countries have identified prevalence of various emotional and behavioral problems similar to this study. A study of 1585 children from a Copenhagen cohort(CCC2000) aged 5-7 years showed the prevalence of any ICD-10 psychiatric disorder to be $5.7 \%$ and behavioral disorders affected $1.5 \%$. More boys were diagnosed with Pervasive developmental disorders (PDD), behavioral disorders and tics [26]. A similar large cross sectional survey in 2007 among the US children aged 6 to 17 years reported a prevalence of $8 \%$ for depression or anxiety, and $5.4 \%$ for behavioral or conduct problems [27]. This study from a single centre estimated at least $0.7 \%$ of the school age population being referred to the secondary care pediatric unit for problematic behaviors each year. This estimate is likely to be less than the actual population prevalence in the community.

A recent comprehensive review of over 160 studies have proven that childhood disabling chronic conditions including ADHD in high-income countries are associated with social disadvantage. There is currently limited evidence to explain the causality of the observed consistent association across different countries [28]. This study confirms a relatively high prevalence of children at high risk of developing ADHD and other behavioral disorders living in the least affluent areas of the community.

ADHD and other behavioral disorders constitute an heterogeneous group of conditions with the etiology involving an interplay of multiple genetic and environmental factors including various potential susceptible gene candidates, with up to $75 \%$ heritability factors [29]. Parental ADHD has been reported to be associated with ADHD symptom severity and persistence into adulthood [30-32]. Prevalence of positive family history in ADHD children varies in different studies. Family history of ADHD has been reported in up to $24 \%$ of ADHD children [32]. This study also recorded high prevalence of ADHD family history in children with both ADHD and other non-ADHD behavioral disorders.

Children with behavior difficulties may also present with many other mental health conditions such as post-traumatic stress disorder, mood disorders and anxiety disorders, or with attachment difficulties in children experiencing many socioeconomic adversities such as maltreatment histories, and many other neuro-developmental or neuro-behavioral disorders such autism, developmental speech, motor, coordination and cognitive delays, sleep or sensory 
integration disorders, as co-morbidities or with overlapping symptoms. Each of these conditions would require prompt assessment and management, which are therefore best conducted within multidisciplinary teams who have access to and knowledge of local practice guidelines which should prompt healthcare providers to explore all the various social, mental health, genetic, developmental, perinatal and educational factors affecting ADHD diagnosis [29, 34, 35].

Behavioral disorders in children often predispose to higher lifetime risks for future mental health disorders. Children diagnosed with a Disruptive Behavior Disorder, especially those with psychopathic traits, are at risk of developing persistent and severe antisocial behavior in adulthood $[2,36,37]$. The high rate of patients being discharged in this study suggests a need for change of paradigm from providing "medical" care model to a longer term multidisciplinary "surveillance " model. Though most of the children with behavior disorders require no medications as first-line treatment, various behavioral therapies for the children and family members often improves their symptoms and levels of distress. Treatment of co-morbid mental health conditions may be needed in the future with ongoing monitoring and surveillance [38]. A general dearth of specialist providers has been recognized as a major barrier to primary care support for the children and adolescents with mental health difficulties [39].

\section{Limitations}

This study has some obvious limitations and the results need to be interpreted with caution. It was a single centre clinical sample and may not truly reflect the entire population of school-age children with behavioral problems in several other regions nationwide. It provides a detailed analysis of a large population of children in a relatively deprive local area. It provides some insight into the relationship between environmental adversity and the prevalence of behavioral disorders in school age children. It also allowed a comparison of the effect of socioeconomic deprivation on the prevalence of ADHD and other behavior disorders in childhood. Additional prospective and larger cohort studies in several areas nationally are needed to confirm the findings of this study.

\section{Conclusion}

Behavioral problems affecting at least $1 \%$ of the schoolage population account for a considerable proportion of community pediatric workload in a local district. The children also have a high level of social, emotional, developmental and educational co-occurring difficulties.

Socioeconomic deprivation appears to be significantly associated with the prevalence of behavior problems in children and adolescents living in the North West of England. Chronic stressors associated with poverty such as singleparenthood and financial worries are hypothesized to cumulatively compromise parental psychological functioning, which in turn negatively affects parenting behavior, leading to less responsiveness and less supportive parenting, compromise child behavioral and mental health outcomes.

Tackling the multiple difficulties of children with behavior problems and supporting their families emphasize the need for an integrated multidisciplinary and multiagency collaboration to ensure the best management outcome for the affected children and their families. Children with behavioral problems require long-term follow-up and surveillance because of their increased risk for future psychopathology into adulthood. Families of children with behavioral problems would also benefit from an integrated multi-disciplinary surveillance because of the higher prevalence of mental health disorders in parents of the affected children. There have been suggestions to screen parents of children with emotional and behavioral problems due to high levels of psychopathology that has been consistently found in several studies [40].

\section{References}

[1] Odgers CL, Caspi A, Russell MA, Sampson RJ, Arseneault L, Moffitt TE. Supportive parenting mediates neighborhood socioeconomic disparities in children's antisocial behavior from ages 5 to 12. Dev Psychopathol. 2012; 24(3):705-21. doi: $10.1017 / \mathrm{S} 0954579412000326$.

[2] Pardini DA, Fite PJ. Symptoms of conduct disorder, oppositional defiant disorder, attention-deficit/hyperactivity disorder, and callous-unemotional traits as unique predictors of psychosocial maladjustment in boys: advancing an evidence base for DSM-V. J Am Acad Child Adolesc Psychiatry.2010;49(11):1134-1144.

[3] Boylan K,Vaillancourt T,Szatmari P. Linking oppositional behavior trajectories to the development of depressive symptoms in childhood. Child Psychiatry Hum Dev. 2012; 43(3):484-97. doi: 10.1007/s10578-011-0277-7.

[4] Raudino A, Woodward LJ, Fergusson DM, Horwood LJ. Childhood conduct problems are associated with increased partnership and parenting difficulties in adulthood. J Abnorm Child Psychol. 2012; 40(2):251-63. doi: 10.1007/s10802-0119565-8.

[5] Latimer K, Wilson P, Kemp J, Thompson L, Sim F, Gillberg C, Puckering C, Minnis H. Disruptive behavior disorders: a systematic review of environmental antenatal and early years risk factors. Child Care Health Dev. 2012; 38(5):611-28. doi: 10.1111/j.1365-2214.2012.01366.x. Epub 2012 Feb 28.

[6] Owens EB, Hinshaw SP. Perinatal Problems and Psychiatric Comorbidity Among Children with ADHD. J Clin Child Adolesc Psychol.2013;42(6):10.1080/15374416.2013.785359. doi:10.1080/15374416.2013.785359.

[7] Loomans EM, Hofland L, van der Stelt O, van der Wal MF, Koot HM, Van den Bergh BR, Vrijkotte TG. Caffeine intake during pregnancy and risk of problem behavior in 5- to 6year-old children. Pediatrics. 2012;130(2):e305-13. doi: 10.1542/peds.2011-3361. [Epub 2012 Jul 9].

[8] Stene-Larsen K, Borge AI, Vollrath ME. Maternal smoking in pregnancy and externalizing behavior in 18-month-old children: results from a population-based prospective study. J Am Acad Child Adolesc Psychiatry. 2009;48(3):283-9. doi: 10.1097/CHI.0b013e318195bcfb. 
[9] Bandiera FC, Richardson AK, Lee DJ, He JP, Merikangas KR. Secondhand smoke exposure and mental health among children and adolescents. Arch Pediatr Adolesc Med. 2011; 165(4):332-8. doi: 10.1001/archpediatrics.2011.30.

[10] Singh GK, Kenney MK, Ghandour RM, Kogan MD, Lu MC. Mental Health Outcomes in US Children and Adolescents Born Prematurely or with Low Birthweight. Depression Research and Treatment. 2013; 2013: 570743. doi: $10.1155 / 2013 / 570743$.

[11] Silva D, Houghton S, Hagemann E, Bower C. Comorbidities of Attention Deficit Hyperactivity Disorder: Pregnancy Risk Factors and Parent Mental Health. Community Ment Health J. 2015;51(6):738-45. doi: 10.1007/s10597-014-9773-0. [Epub 2014 Sep 2].

[12] Tai YC, Chi MH, Chu CL, Chiu NT, Yao WJ, Chen PS, Yang YK. Availability of Striatal Dopamine Transporter in Healthy Individuals With and Without a Family History of ADHD. J Atten Disord. 2016 Jul 7. pii: 1087054716654570. [Epub ahead of print].

[13] Boden JM, Fergusson DM, Horwood LJ. Risk factors for conduct disorder and oppositional/defiant disorder: evidence from a New Zealand birth cohort. J Am Acad Child Adolesc Psychiatry. 2010; 49(11):1125-33. doi: 10.1016/j.jaac.2010.08.005. [Epub 2010 Sep 26].

[14] Evans GW, Vermeylen FM, Barash A, Lefkowitz EG, Hutt RL. The experience of stressors and hassles among rural adolescents from low-and middle-income households in the USA. Children, Youth and Environments. 2009;19(2):164-175.

[15] McLoyd VC. The impact of economic hardship on Black families and children: Psychological distress, parenting, and socioemotional development. Child Development. 1990; 61(2):311-346.

[16] Schiffer B, Leygraf N, Müller BW, Scherbaum N, Forsting M, Wiltfang J, Gizewski ER, Hodgins S. Structural brain alterations associated with schizophrenia preceded by conduct disorder: a common and distinct subtype of schizophrenia? Schizophr Bull. 2013; 39(5):1115-28. doi: 10.1093/schbul/sbs115. Epub 2012 Sep 26.

[17] Sebastian CL, McCrory EJ, Cecil CA, Lockwood PL, De Brito SA, Fontaine NM,Viding E. Neural responses to affective and cognitive theory of mind in children with conduct problems and varying levels of callous-unemotional traits. Arch Gen Psychiatry. 2012; 69(8):814-22. doi: 10.1001/archgenpsychiatry.2011.2070.

[18] Raudino A, Fergusson DM, Woodward LJ, Horwood LJ. The intergenerational transmission of conduct problems. Soc Psychiatry Psychiatr Epidemiol. 2013;48(3):465-76. doi: 10.1007/s00127-012-0547-0. [Epub 2012 Jul 5].

[19] Strickland J, Hopkins J, Keenan K. Mother-teacher agreement on preschoolers' symptoms of ODD and CD: does context matter? J Abnorm Child Psychol. 2012; 40(6):933-43. doi: 10.1007/s10802-012-9622-y.

[20] Furlong M, McGilloway S, Bywater T, Hutchings J, Smith SM, Donnelly M Cochrane review: behavioral and cognitivebehavioral group-based parenting programmes for early-onset conduct problems in children aged 3 to 12 years (Review). Evid Based Child Health. 2013; 8(2):318-692. doi: 10.1002/ebch.1905.
[21] Liber JM, De Boo GM, Huizenga H, Prins PJ. School-based intervention for childhood disruptive behavior in disadvantaged settings: a randomized controlled trial with and without active teacher support. J Consult Clin Psychol. 2013; 81(6):975-87. doi: 10.1037/a0033577. [Epub 2013 Jul 8].

[22] Shelton KH, Collishaw S, Rice FJ, Harold GT, Thapar A. Using a genetically informative design to examine the relationship between breastfeeding and childhood conduct problems. Eur Child Adolesc Psychiatry. 2011; 20(11-12):5719. doi: 10.1007/s00787-011-0224-y. [Epub 2011 Oct 26].

[23] Marmot M, Friel S, Bell R, Houweling TAJ, Taylor S. Commission on Social Determinants of Health. Closing the gap in a generation: Health equity through action on the social determinants of health. Lancet. 2008; 372(9650):1661-1669.

[24] World Health Organization. Commission on Social Determinants of Health. Closing the gap in a generation: health equity through action on the social determinants of health. Final Report of the Commission on Social Determinants of Health. Geneva; 2008.

[25] Department for Communities and Local Government UK). The English Indices of Deprivation 2015. Sept 2015.

Available online:

https://www.gov.uk/government/uploads/system/uploads/attac hment_data/file/465791/English_Indices_of_Deprivation_201 5_-_Statistical_Release.pdf

[26] Elberling H, Linneberg A, Rask CU, Houman T, Goodman R, MetteSkovgaard A. Psychiatric disorders in Danish children aged 5-7 years: A general population study of prevalence and risk factors from the Copenhagen Child Cohort (CCC 2000). Nord J Psychiatry. 2016;70(2):146-55. doi: 10.3109/08039488.2015.1070199. [Epub 2015 Oct 28].

[27] Ghandour RM, Kogan MD, Blumberg SJ, Jones JR, Perrin JM. Mental health conditions among school-aged children: geographic and sociodemographic patterns in prevalence and treatment. J Dev Behav Pediatr. 2012; 33(1):42-54. doi: 10.1097/DBP.0b013e31823e18fd.

[28] SpencerNJ, BlackburnCM, ReadJM. Disabling chronic conditions in childhood and socioeconomic disadvantage: a systematic review and meta-analyses of observational studies. BMJ Open 2015; 5:e007062doi:10.1136/bmjopen-2014-007062

[29] National Institute for Health and Care Excellence(NICE). Diagnosis and Management of ADHD in Children, Young People and Adults. Clinical Guidelines No. 72. 2009. Online: http://www.nice.org.uk/CG72. Last accessed September 2016

[30] Kaye S, Ramos-Quiroga JA, van de Glind G. et al. Persistence and Subtype Stability of ADHD Among Substance Use Disorder Treatment Seekers. J Atten Disord. 2016 Feb 27. pii: 1087054716629217. [Epub ahead of print].

[31] vanLieshout M, Luman M, Twisk JW et al. A 6-year followup of a large European cohort of children with attentiondeficit/hyperactivity disorder-combined subtype: outcomes in late adolescence and young adulthood. Eur Child Adolesc Psychiatry. 2016; 25(9):1007-17. doi: 10.1007/s00787-0160820-y. [Epub 2016 Feb 2].

[32] Lecendreux M1, Konofal E, Cortese S, Faraone SV.A 4-year follow-up of attention-deficit/hyperactivity disorder in a population sample. J Clin Psychiatry. 2015; 76(6):712-9. doi: 10.4088/JCP.14m09555. 
[33] Bonati M, Reale L, Zanetti M- et al. A Regional ADHD Center-Based Network Project for the Diagnosis and Treatment of Children and Adolescents With ADHD. J AttenDisord. 2015 Aug 28. pii: 1087054715599573. [Epub ahead of print]

[34] Klein B, Damiani-Taraba G, Koster A, Campbell J, Scholz C. Diagnosing attention-deficit hyperactivity disorder (ADHD) in children involved with child protection services: are current diagnostic guidelines acceptable for vulnerable populations? Child Care Health Dev. 2015; 41(2):178-85. doi: 10.1111/cch.12168. [Epub 2014 Jun 18].

[35] Section On Complementary And Integrative Medicine; Council on Children with Disabilities; American Academy of Pediatrics, Zimmer M, Desch L. Sensory integration therapies for children with developmental and behavioral disorders. Pediatrics. 2012; 129(6):1186-9. doi: 10.1542/peds.20120876. [Epub 2012 May 28].

[36] Boylan K, Vaillancourt T, Szatmari P. Linking oppositional behavior trajectories to the development of depressive symptoms in childhood. Child Psychiatry Hum Dev. 2012; 43(3):484-97. doi: 10.1007/s10578-011-0277-7.
[37] McMahon RJ, Witkiewitz K, Kotler JS. Predictive validity of callous-unemotional traits measured in early adolescence with respect to multiple antisocial outcomes. J Abnorm Psychol 2010; 119(4):752-63. doi: 10.1037/a0020796.

[38] Riley M, Ahmed S, Locke A. Common Questions About Oppositional Defiant Disorder. Am Fam Physician. 2016; 93(7):586-91.

[39] O'Brien D, Harvey K, Howse J, Reardon T, Creswell C. Barriers to managing child and adolescent mental health problems: a systematic review of primary care practitioners' perceptions. $\mathrm{Br} \mathrm{J}$ Gen Pract. 2016; doi: 10.3399/bjgp16X687061. pmid:27621291.

[40] Middeldorp CM, Wesseldijk LW, Hudziak JJ, Verhulst FC, Lindauer RJ, Dieleman GC. Parents of children with psychopathology: psychiatric problems and the association with their child's problems. Eur Child Adolesc Psychiatry. 2016; 25(8):919-27. doi: 10.1007/s00787-015-0813-2. [Epub 2016 Jan 13]. 